\title{
PERALATAN PERANG NICA DALAM MENGHADAPI PEJUANG PADA MASA REVOLUSI FISIK DI BALI TA- HUN 1945 - 1950
}

\author{
Ida Bagus Astika Pidada \\ Universitas Warmadewa \\ astikapidada@gmail.com
}

\begin{abstract}
ABSTRAK
Menyerahnya tanpa syarat Letnan Jendral H. Ter Pooerten ( Panglima Angkatan Perang Hindia Belanda) atas nama Angkatan Perang Serikat di Indonesia kepada Letnan Jendral Hitosyi Imamura (Pimpinan Angkatan Perang Jepang), sejak saat itu pemerintah Hindia Belanda berakhir di Indonesia. Pada waktu itu serdadu - serdadu Belanda yang menjadi tawanan perang Jepang karena tidak sempat lari ke Australia banyak yang dikirim kepedalaman Siam dan Birma untuk membuka hutan, dan membuat jembatan serta jalan kereta api. Pada tanggal 15 Agustus 1945 Jepang akhirnya menyerah kalah kepada Sekutu. Kekalahan Jepang ini menyebabkan orang - orang Belanda yang menjadi tawanannya dengan cepat mengadakan latihan persiapan kembali ke Indonesia. Kedatangan Belanda di Bali mendapat perlawanan dari para pejuang di bawah pimpinan Letnan Kolonel I Gusti Ngurah Rai. Meskipun persenjataan yang dimiliki para pejuang di Bali terbatas namun perjuangan cukup lama dapat bertahan. NICA dalam menghadapi para pejuang di Bali pada masa revolusi fisik sudah menggunakan peralatan perang modern seperti: kapal terbang pipercub, kapal terbang lucked, motor bot, truk, jeep, telepon, bren, mitraliur, stengun, mortir, lichthalon dan lain - lain namun tidak mudah dapat mengalahkannya. Hal ini disebabkan karena antara pejuang dengan rakyat di Bali bersatu.
\end{abstract}

Kata kunci: peralatan perang, NICA, pejuang

\begin{abstract}
[Title: The Nica War Equipment in Facing Patriots in Physical Revolution in Bali In 1945 - 1950] Giving up without the conditions of Lieutenant General H. Ter Poorten (Commander of the Dutch East Indies) on behalf of the United States Army in Indonesia to Liuetenant General Hiroshi Imamura (Japanese Army Leader). Since the Dutch East Indies government ended in Indonesia. At that time Dutch soldiers who were Japanese prisoners of war because they did not have time to flee to Australia were sent to the interior of Siam and Birma to clear forests and make bridges and railways. On August $15^{\text {th }}$ 1945, Japan finally surrendered to allies. This defeat of Japan caused the captives of the Dutch to quickly hold preparatory exercises back to Indonesia. The arrival of the Dutch in Bali received resistance from the fighters under the leadership of Lieutenant Colonel I Gusti Ngurah Rai. Although the weapons possessed by fighters in Bali is limited but the struggle is long enough to survive. NICA in the face of fighters in Bali during the physical revolution has used modern war equipment such as: pipercub airplanes, lucked airplanes, motorbikes, jeeps, telephones, bren, mitraliur, stengun, mortar, lichthalon and others but not easy can beat him. This is because the fighters with the people in Bali are united.
\end{abstract}

Keywords: war equipment, NICA, patriots 


\section{PENDAHULUAN}

Menyerahnya tanpa syarat Letnan Jendral H.Ter Pooerten (Panglima Angkatan Perang Hindia Belanda) atas nama Angkatan Perang Serikat di Indonesia kepada Letnan Jendral Hitosyi Imamura (pimpinan Angkatan Perang Jepang) maka sejak itu pemerintah Hindia Belanda berakhir di Indonesia (Sartono Kartodirdjo (dkk.), 1977 : 5). Pada waktu ini Hindia Belanda masuk persekutuan ABCD (Amerika,Britain, China and Duth) sehingga perlu dikuasai oleh Jepang. Pada waktu itu serdadu Belanda banyak menjadi tawanan Jepang karena tidak sempat lari ke Australia seperti Merine dan KNIL. Tawanan ini di kirim ke pedalaman Siam dan Birma untuk membuka hutan, membuat jembatan dan jalan kereta api. Jembatan yang terkenal yaitu " The Bridge Over Kwai" yaitu di Sungai Kwai (Nyoman S. Pendit, 1979 : 140).

Jepang akhirnya menyerah kepada Sekutu pada tanggal 15 Agustus 1945 dimana penandatanganan penyerahan ini dilalukan di atas geladak kapal perang Amerika "Missouri" tanggal 2 September 1945. Kalahnya Jepang, orang - orang Belanda yang menjadi tawanan ini dengan cepat mengadakan latihan persiapan kembali ke Indonesia.

Rombongan pertama Brigade Y pada tanggal 2 Maret 1946 mulai di daratkan di sepanjang pantai Sanur. Gajah Merah julukan lain yang diberikan kepada Brigade Y. Mendaratnya pasukan Gajah Merah, situasi di Bali menjadi semakin genting serta tidak tenang sehingga pasukan Belanda yang ada di Lombok sebanyak 3 kompi di tarik ke Bali.

Di Bali pasukan Belanda mendapat perlawanan dari para pejuang di bawah pimpinan Letnan Kolonel I Gusti Ngurah Rai. Persenjataan yang dimiliki para pejuang di Bali sangat terbatas meskipun demikian perjuangan cukup lama dapat bertahan. Untuk itu Belanda (NICA) menggunakan berbegai peralatan perang agar dapat mengalahkan setiap perlawanan yang dilakukan oleh para pejuang pada masa revolusi fisik di Bali.

\section{METODE}

Metode yang digunakan dalam penulisan ini adalah metode sejarah. Metode sejarah adalah merupakan alat yang dimiliki oleh disiplin ilmu sejarah untukm menyusun sejarah (Nugroho Notosusanto, 1978 : 10). Metode sejarah memberi bantuan secara efektif dalam pengumpulan bahan - bahan sejarah, menilai secara kritis, dan kemudian menyajikan dalam suatu sintesa dari hasil hasilnya. Proses metode sejarah ada 4 (empat) tahap yakni : heuristik, kritik sumber, interpretasi, dan historiografi. Dengan menggunakan metode ini penulisan tentang "Peralatan Perang NICA Dalam Menghadapi Pejuang Pada Masa Revolusi Fisik Yang Terjadi Di Bali Pada Tahun 1945 - 1950 “ dapat disusun.

\section{PEMBAHASAN}

Peralatan oleh Poerwadarminta diartikan kelengkapan, perbekalan, berbagai alat perkakas. Begitu pula dengan perang diartikan pertempuran menggunakan senjata antar Negara (Poerwadarminta, 1976: 30). Sedangkan pejuang diartikan orang yang berjuang (Poerwadarminta, 1976: 723).

Sedangkan pengertian revolusi ada beberapa pendapat yang dapat dikemukakan seperti A.H. Nasution mengatakan revolusi diartikan meruntuhkan sistem - sistem lama (Nasution, 1977). Demikian halnya dengan I Nyoman Dekker mengatakan bahwa revolusi adalah suatu perubahan yang sifatnya cepat dan 
fundamental dimana terjadi dalam waktu singkat (I Nyoman Dekker, 1980: 1314) . Begitu pula halnya dengan (Kartodirdjo, 1970: 12)

menyebutkan revolusi itu suatu proses politik yang biasanya timbul pada situasi kritis dalam hal ini golongan - golongan yang konflik mengusahakan perubahan - perubahan politik yakni dengan cara - cara radikal. Dengan demikian dapat disimpulkan revolusi adalah perubahan secara cepat sifatnya fundamental dimana terjadi pada situasi kritis dalam hal ini golongan - golongan yang konflik berusaha meruntuhkan sistem - sistem lama secara radikal dengan menggantikan dengan sistem - sistem yang baru.

Demikian halnya ketika terjadi revolusi fisik di Bali para pejuang mendapat perlawanan dari pasukan Belanda (NICA). Belanda menggunakan berbagai peralatan perang modern agar dapat mengalahkan setiap perlawanan yang dilakukan oleh para pejuang di Bali. Meskipun Belanda (NICA) dengan peralatan yang jauh lebih modern, mereka tidak mudah dapat mengalahkan para pejuang di Bali. Ini membuktikan perjuangan di Bali cukup lama dapat bertahan.

Periode waktu peristiwa ini terjadi dari tahun 1945 sampai tahun 1950. Tahun 1945 digunakan sebagai batasan awal karena setelah proklamasi, Belanda (NICA) ingin berkuasa di Bali sehingga timbul perlawanan dari para pejuang untuk menentang penjajah. Sedangkan tahun 1950 sebagai batasan akhir karena ditandai dengan adanya penurunan gerilya di Bali berhubung karena adanya pengakuan kedaulatan.

Pada masa revolusi fisik di Bali Belanda (NICA) menggunakan berbagai macam peralatan perang untuk menghadapi para pejuang antara lain :

Motor bot. Setelah kurang lebih tiga bulan I Gusti Ngurah Rai berada di Jawa atas bantuan pasukan ALRI Banyuwangi sekitar pukul 20.00 malam pada tanggal 3 April 1946 berangkat dari Muncar menuju Bali. Kira - kira pukul 03.00 pagi dari arah timur muncul 2 buah motor bot Belanda yang mengadakan patroli. Tentara Belanda dalam hal ini telah mengetahui bahwa perahu yang lewat tersebut tidak lain adalah para pejuang. Tanpa komentar Belanda melancarkan tembakan senjata otomatisnya. Ketika peristiwa ini terjadi gugur Cokorda Gambir dan Cokorda Dharma Putra, sedangkan Cokorda Oka Sudarsana beserta tukang jukungnya ditangkap (Pendit, 1979: 115-117).

Kapal terbang capung/Pipercub. Ketika I Gusti Ngurah Rai berada di Munduk Malang pada suatu malam mendapat laporan rahasia bahwa besok serdadu NICA akan mengadakan patroli di sekitar desa tersebut. Pasukan NICA mengirim pasukannya sebanyak 2 peleton menuju desa ini. Selanjutnya pasukan NICA disambut oleh peleton Tiaga dan Gelebes. Dalam pertempuran di pihak pejuang ada yang kena tembak saudara Soeprapto. Sedangkan NICA yang datang dari barat disambut oleh peleton Sardja. Rupa - rupanya Belanda terus mendengar tembakan, mereka ragu - ragu untuk maju. Kira - kira pukul 14.00 datanglah kapal terbang capung melakukan pengintaian dari udara. Supaya tidak di serang lebih dahulu Tiaga menembak dengan brennya. Taka Haki ( I Made ) disuruh memegang kaki bren di atas pundaknya. Pada waktu itu kapal terbang capung kena tembak dan hampir jatuh. Melihat hal ini pasukan pejuang bersorak kegirangan selanjutnya kapal tersebut memutar keselatan dan menghilang (Pendit, 1979 : 31-32).

Pesawat bomber (luckeed). Setelah kapal terbang capung menghilang di Munduk Malang, kira - kira setengah jam kemudian datanglah pesawat bomber (luckeed) yang memuntahkan peluru kepada pasukan pejuang. Pertempuran di 
Munduk Malang berlangsung antara para pejuang dengan NICA hingga sore hari (Yayasan Kebaktian Proklamasi Daerah Propinsi Bali, 1968: 9). Demiukian pula pada waktu terjadi pertempuran di Subak Uma Kaang Marga tentara Belanda tidak berani maju bahkan mereka mundur. Para pemuda gerilya bersorak - sorai, sambil memekikkan "Merdeka" berkali - kali. Pasukan pada waktu ini bergembira dengan semangat berkobar - kobar mereka bangkit mengejar serdadu - serdadu NICA yang terus mundur itu. Ada yang mundur sampai di bagian sebelah barat Desa Tunjuk, terus sampai ke bagian selatan Desa Marga. Pasukan NICA yang ada di bagian Timur mundur terus sampai ke sungai Sungi. Pasukan Ciung Wanara memiliki kesempatan menyusun kembali stellingnya. Agar medan menjadi lebih luas, pasukan dibagi atas tiga barisan. Barisan depan, sayap kanan dan sayap kiri. Sedangkan pemimpin pasukan berada di tengah - tengah. Waktu sudah menjelang tengah hari. Mendadak, sayup - sayup terdengar deru pesawat di udara. Sebuah pesawat pengintai kecil (jenis pipercub atau sering dijuluki kapal capung) muncul berputar - putar di udara. Ketika pesawat itu mencoba terbang rendah pasukan "Ciung Wanara" menembaknya dengan senapan dan bren. Entah kena atau tidak pesawat kecil tersebut, pesawat itu tidak muncul lagi lenyap dibalik gulungan awan dan asap mesiu. Namun tidak lama kemudian muncul pesawat pembom dan pesawat tempur. Pasukan induk "Ciung Wanara" dihujani bom dan tembakan mitralyur dari udara. Para pejuang bagaikan banteng, nekad maju menyerbu di tengah - tengah hujan peluru. Pasukan NICA sangat kaget, nyalinya menciut melihat kenekatan para pemuda gerilya tersebut. Mereka terus melepaskan tembakan gencar dari persembunyiannya. Sementara dari udara bom - bom terus juga berjatuhan. Satu persatu para pemuda pejuang itu akhirnya gugur (Suralaga, 1982).

Truk. Setelah kurang lebih 40 hari pasukan I Gusti Ngurah Rai mengadakan long march sampailah akhirnya di Tanah Aron. Di Tanah Aron pasukan mengalami kelelahan karena hampir sepanjang perjalanan terus bertempur dan hanya dapat istirahat sebentar. Kurang lebih pukul 19.00 sedang enaknya istirahat dan bersenda gurau, tiba - tiba Letnan Kolonel I Gusti Ngurah Rai menerima laporan dari seorang penyelidik bahwa seluruh pos NICA di Karangasem dikerahkan untuk menggempur pasukan induk. Pagi hari terdengar deruan mobil dari jauh berupa iring - iringan truk NICA yang berjumlah 35 buah, masing - masing mulai mendekat diantaranya satu peleton NICA totok. NICA rupanya sudah mengetahui kedudukan pasukan induk. Di pihak pejuang atau pasukan induk telah siap menerima kehadiran mereka. Pada tanggal 7 Juli 1946 pukul 09.00 pagi letusan pertama terjadi di sebelah selatan yaitu di Gunung Pawon dan pertempuran ini berlangsung hingga pukul 15.00 sore. Dalam pertempuran ini pasukan NICA tewas sebanyak 82 orang. Sedangkan dipihak pasukan induk tidak ada korban (Pindha, 1964: 4-13). Di daerah Negara, kendaraan truk digunakan oleh NICA untuk mengangkut pejuang yang gugur. Pintu bak belakang truk sengaja dibuka agar mayat dilihat oleh penduduk. Mayat di arak keliling kota dengan kepala menghadap ke belakang truk. Adapun tujuannya agar mental para pejuang jatuh dan rakyat takut kepada NICA (I Ketut Weda, 1985).

Kendaraan truk juga pernah digunakan oleh tentara NICA ketika pasukan I Gusti Ngurah Rai sampai di Desa Marga setelah berhasil menggerebeg tangsi polisi NICA di kota Tabanan tanggal 18 Nopember 1946 tanpa pertumpahan darah. Setelah melancarkan aksinya, malam itu juga pasukan " Ciung Wanara " menghilang dari kota Tabanan. Keesokan paginya berita aksi itu telah tersebar ke 
segala penjuru. Rakyat sangat kagum dan memujinya, sebaliknya Belanda sangat geram dan marah. Nica melakukan penyelidikan melalui mata - matanya dimana pasukan Ciung Wanara " berada. Menjelang pagi hari, para pejuang tiba di Banjar Ole Desa Marga dalam kondisi yang sangat lelah. Penduduk desa menyambutnya dengan gembira. Mereka menyediakan makanan dan mengurus tempat tidur pasukan yang kelelahan itu. Sore harinya seluruh anggota pasukan mendapat hiburan tari janger yang khusus di datangkan dari Desa Tunjuk. Pertunjukan didahului peragaan pencak silat yang dilakukan oleh anggota - anggota pasukan. Bahkan Letkol I Gusti Ngurah Rai ikut pula terjun ke arena, yang disambut dengan tepuk tangan meriah oleh rakyat. Hiburan sore hari itu sangat mengesankan dan menjadi bukti adanya ikatan bathin yang kuat antara rakyat dengan para pejuang. Malam harinya seluruh anggota pasukan menuju pura Dalem Basa untuk bersembahyang memohon perlindungan kepada Tuhan Yang Mahaesa. Persembahyangan diakhiri dengan pekik "Merdeka" berkali - kali, disusul dengan seruan "Sekali Merdeka Tetap Merdeka dan pasti Merdeka" dengan gemuruh dan gegap gempita. Setelah mendapat laporan situasi aman, malam itu juga Induk Pasukan bergerak perlahan - lahan meninggalkan Banjar Ole menuju Desa Kelaci. Para pejuang disini disambut oleh rakyat dengan penuh semangat dan gembira. Disini Induk pasukan beristirahat. Secara mendadak penghubung laskar rakyat Marga menerima berita, bahwa pasukan Belanda secara tiba - tiba muncul di Desa Marga bagian selatan yang berkekuatan 60 orang dengan persenjataan lengkap. Selain itu datang pula laporan lainnya bahwa pasukan Belanda sudah mulai bergerak di bagian utara dari Desa Marga. Desa Marga sudah mulai dikepung oleh pasukan Belanda. Rupanya musuh berhasil menelusuri jejak perjalanan pasukan "Ciung Wanara". Letkol I Gusti Ngurah Rai segera menyiapkan pasukannya. Mereka berjumlah 70 orang. Semuanya tegang namun bersemangat. Matahari baru saja muncul, terdengar deru kendaraan NICA di jalan raya. Truk truk NICA melintas dari Desa Marga ke jurusan Desa Tunjuk. Mereka melewati Desa Kelaci, dimana induk pasukan I Gusti Ngurah Rai sedang bersembunyi dan bersiap - siap dengan stelingnya. Desa Marga mulai diteror oleh Belanda. Penduduk diperintahkan kumpul di pasar Marga. Tua muda, laki perempuan dan bahkan anak - anak. Mereka disiksa, dipukul, ditendang dan beberapa orang ditembak. NICA tidak berhasil memperoleh informasi dari rakyat, selanjutnya pasukan NICA menyebar ke segala penjuru. Mereka memasuki daerah persawahan Uma Kaang. Tanpa disadari puluhan moncong senjata menanti mereka yang siap memuntahkan peluru. Sementara truk - truk NICA terus menderu - deru di jalan raya. Pasukan NICA pada waktu ini terus mendekat ke pasukan Ciung Wanara yang sudah siap menarik pelatuk senjatanya. Pasukan Ciung Wanara tinggal menunggu isyarat dari pemimpinnya untuk menembak. Waktu telah menunjukkan pukul 09.00 pagi dan dalam detik - detik yang menegangkan tiba tiba terdengar letusan dari mulut pistol Letkol I Gusti Ngurah Rai tanda pertempuran di mulai (Suralaga, 1982).

Demikian dengan pertempuran di Desa Ringdikit. Pada tanggal 4 April 1946 satu kompi pasukan ALRI mendarat di pantai Yeh Biu Celukanbawang dipimpin Letnan Waroka dan Letnan GID Wiyono. Besoknya pagi - pagi buta pasukan menuju Seririt mengendarai 40 dokar menuju Desa Bubunan. Di desa tersebut, pasukan diterima oleh Putu Dana. Ketika semua anggota pasukan sedang menikmati hidangan, datang informasi 2 truk tentara NICA turun di Desa Ringdikit. Meskipun hidangan belum selesai dinikmati, komandan memberikan in- 
struksi pasukan bergerak ke arah selatan. Selain itu mendapat bantuan pemuda pemuda tanpa membawa senjata, juga ikut seorang Jepang namanya Bung Ali membantu perjuangan para pemuda. Tiba di tingkungan Ringdikit, terjadilah kontak senjata dengan pasukan NICA. Posisi NICA dalam hal ini lebih menguntungkan dari pasukan ALRI sehingga dengan mudah menekan tembakan - tembakan gencar. Melihat keadaan medan, secepat kilat Bung Ali mengambil alih senjata milik ALRI yang gugur, kemudian dengan sigap beralih ke posisi yang agak tinggi. Setelah medan dapat dikuasai, Bung Ali dengan lihainya memberondong pasukan Gajah Merah Nica Itu, hingga satu persatu tentara NICA tewas. Berhubung banyaknya tentara NICA yang tewas, pasukan musuh (NICA) melarikan diri sambil mengangkat temannnya yang tewas ke atas truk menuju arah selatan. Pertempuran di Ringdikit berlangsung selama 2 jam. Setelah selesai pertempuran, pasukan ALRI mengadakan apel dan ternyata yang gugur dipihak pejuang Letnan Muda Willem. Letnan Muda Willem selanjutnya dikebumikan di kuburan Desa Bubunan. NICA yang merasa tidak puas atas kekalahan ini, pada tanggal 6 April 1946 membumianguskan Desa Ringdikit. Pasukan ALRI selanjutnya kembali ke induk pasukannya di Banyuwangi (Tim Bali Post, 1988)

Begitu halnya dengan pertempuran di Desa Sekumpul pada waktu terjadi long march pasukan MBO ke Gunung Agung. Pada tanggal 1 Juni 1946 berangkatlah pasukan MBO dari Bengkel Anyar menuju Desa Gesing, dan dari sini bergerak ke arah timur. Pasukan Buleleng dipimpin Kapten Suwija segera menggabungkan diri. Sepanjang perjalanan pasukan MBO melakukan pertempuran dengan pos - pos NICA terdekat seperti : pertempuran Bebetin, Sekumpul dan Lemukih. Sebelum itu pos NICA di Desa Sudaji digempur habis - habisan. Pertempuran Di Desa Bebetin digambarkan sebagai pertempuran yang cukup seru. Kemudian merembet ke Desa Sekumpul dan Desa Lemukih pada tanggal 10 Juni 1946. Pertempuran terus berkobar selama 14 hari. Para pemuda yang dipelopori Kap;ten Suwija, Anang Ramli, Serutu dibantu pemuda - pemuda lainnya seperti Loka, Sutama, Dewa Tjintia, Ida Bagus Indra dan lain - lain memusatkan kekuatan di tempat yang strategis, sehingga dengan mudah memberikan pukulan terhadap NICA yang kebanyakan terdiri dari tentara - tentara Gurkha. Rakyat Bebetin, Sekumpul dan Lemukih bersatu membantu perjuangan para pemuda, terutama menyediakan perbekalan digaris belakang. Para wanita dengan berpakaian bersih turut membawakan makanan dan mengusahakan tempat - tempat peristirahatan. Pada suatu hari yang cukup cepatberistirahat sambil makan di dalam sekolah. Hal itu dilihat oleh pasukan pemuda yang mengintai dari tempat yang agak tinggi. Sedang enak - enaknya pasukan NICA beristirahat, tiba - tiba para pemuda pejuang melepaskan tembakan gencar, menyebabkan pasukan NICA konyol tidak bisa berkutik. Rentetan peluru mitraliur yang dibidikkan oleh Bung Ali membinasakan pasukan NICA tadi, sisanya kocar - kacir lalu cepat - cepat kembali ke Singaraja. Kekalahan tentara NICA kembali datang dengan pasukan yang lebih besar. Tentara NICA yang datang membakar Desa Bebetin serta menangkapi rakyat yang tidak bersalah. Agar tidak terjadi korban di pihak rakyat, pasukan MBO mundur ke Banjar Nangka, kemudian melanjutkan perjalanan ke daerah selatan terus ke timur (Bali Post, 1985).

Jeep. Kendaraan jeep sering digunakan oleh pimpinan tentara NICA pada waktu patroli menuju Desa Rendang (Karangasem) yang berangkat dari kota Klungkung. Pimpinan tentara NICA yang sering menggunakan jeep adalah Letnan Garo, Letnan Bon Stovel, dan Smith (Ngakan Putu Arka Sudewa, 1985) 
Telepon. Pesawat telepon juga pernah digunakan oleh Belanda pada waktu menghadapi pasukan Ciung Wanara yang dipimpin oleh I Gusti Ngurah Rai di Margarana. Hal ini terbukti dengan adanya bantuan pasukan yang datang dalam waktu relatif singkat dengan menggunakan pesawat udara (Pancer Ardana, 1985).

Bren. Ketika pasukan I Gusti Ngurah Rai menyebrang dari Muncar (Banyuwangi) ke Bali, Kira - kira menjelang pukul 3 malam di dekat pantai antara Cupel dan Candi Kusuma terlihat benda - benda hitam bergerak semakin mendekat menuju arah rombongan yang ditumpangi oleh Cokorda Darmaputra dan Cokorda Ngurah Gambir. Dua motor boat patroli Belanda tersebut menghampiri dan menanyakan siapa - siapa yang berada dalam jukung sambil mengadakan pemeriksaan. Cokorda Oka dan kawan - kawan menjawab pertanyaan Belanda tidak berterus terang. Cokorda Oka dan kawan - kawan menyatakan dirinya sebagai tukang pancing ikan. Belanda dalam hal ini tidak percaya karena melihat perlengkapan di dalam jukung tersebut ada topi baja, granat tangan dan sejumlah senjata dan perlengkapan militer lainnya. Tanpa tanya lagi, Belanda terus melancarkan tembakan dengan senjata otomatisnya yaitu bren dari jarak dekat kurang lebih 5 meter. Penembakan ini terjadi pada satu perahu, sedangkan perahu - perahu yang lainnya masih jauh tidak kelihatan dari kejadian ini. Gencarnya tembakan Belanda, menyebabkan pasukan kita dalam perahu tidak sempat membalasnya dengan senjata yang tidak otomatis dibawanya. Namun demikian sempat melemparkan beberapa granat ke arah patroli Belanda untuk mencegah penembakan - penembakan Belanda lebih lanjut. Di pihak kita gugur 2 orang tentara yaitu Cokorda Ngurah Gambir dan Cokorda Darmaputra serta seorang nelayan berasal dari Negara (Suparsa, 1982).

Badik, Arit Besar, Tombak, Bambu Runcing Dan Bandil. Sekembalinya pasukan I Gusti Ngurah Rai dari Tanah Aron sampailah pada sebuah kampung (diperkirakan kampung Sonda ). Di kampung ini dilihat semua orang laki - laki berderet di jalanan kecil itu membawa senjata. Ada diantara mereka membawa badik, arit besar, tombak, bambu runcing dan ranting - ranting pohon berduri panjang yang disebut "bandil". Bandil ini dipasang melingkar di ujung bambu dengan garis tengah kira - kira setengah meter. Mula - mula para pejuang heran melihat orang - orang tersebut namun segera dapat mengerti karena orang - orang kampung tersebut adalah bodoh. Orang - orang kampung itu mendapat perintah dari Belanda (NICA) untuk menjaga kampungnya karena para pemuda yang datang akan "merampok". Orang - orang itu kelihatan ragu - ragu dan tegang mungkin karena mereka tidak tahu siapakah yang melalui kampungnya ini. Melihat keadaan ini I Gusti Ngurah Rai mengintruksikan " kita berjalan terus, jangan mengganggu orang - orang kampung dan jangan masuk kampung". Perintah itu dioper ke belakang dan ke muka. Meskipun demikian ada juga kawan - kawan yang tidak disiplin mereka perlu mengetahui apa sebenarnya yang hendak diperbuat oleh orang kampung itu. "Hai untuk apa ini" tanya anak - anak kepada salah seorang yang memegang bandil di pinggir jalan. Dalam bahasa daerah "punika anggen ngejuk pemuda" (ini untuk menangkap pemuda) jawab orang itu. "Kengkenang ngejuk" (bagaimana caranya menangkap). "Tangkeb antuk puniki" (di jerat dengan ini) sahut orang itu sambil menunjuk bandilnya. Orang tersebut tidak mengetahui bahwa yang diajak bicara adalah pemuda yang harus ditangkap dengan bandil itu. Nah Pak Rai hendak ditangkap (ditangkeb) dengan bandil itu kataku bergurau (I Gusti Ngurah Pindha) dengan Pak Rai yang berjalan 
di sampingku. "Yah, kalau kepala kita masuk di bandil itu tidak bisa ke luar lagi" sahut Pak Rai sambil tertawa. Seorang pemuda yang membawa sten tidak dapat menahan rasa marahnya. "Kalau pemuda ini membawa begini kamu berani menangkapnya" katanya dengan gemas sambil ngokang stennya. Pada waktu itu I Gusti Ngurah Pindha sudah agak jauh dimuka mendengarnya. I Gusti Ngurah Pindha menoleh dan melihat orang yang digertak itu membuang senjatanya dan jongkok dengan serentak. Beberapa orang mengangkat tangannya di sebelah telinganya sambil ragu - ragu mengucapkan "Mereka" (maksudnya "Merdeka"). Kami semua tertawa melihat keadaan yang lucu itu (Pindha, 1968b).

Lichthalon. Sekembalinya pasukan I Gusti Ngurah Rai dari Tanah Aron sampailah di Desa Pengajaran. Ketika alam sudah mulai terang berhentilah I Gst Ngr. Pindha pada sebuah hutan kecil dimana terdapat sungai yang agak besar dan berbatu. Pada celah - celah batu tersebut mengali air yang sangat jernih. Disini para pejuang ada yang mandi dan mencuci pakaian. I Gst Ngr Pindha dengan beberapa kawan pada waktu itu memperoleh tempat di sebuah gubuk kecil. Di tempat tersebut kemudian mereka melepaskan lelah. Demikian pula Pak Rai, Pak Wisnu dan beberapa anggota stafnya ikut beristirahat pula pada sebuah bale di sebuah rumah kecil. Sementara itu ada pula yang melakukan kegiatan memetik jagung serta membakarnya. Kira - kira jam 4 sore I Gst Ngr Pindha terperanjat melihat seekor burung gagak terbang dengan cepat di atas gubuknya. Burung tersebut mengeluarkan suara nyaring berulang - ulang seolah - olah sangat tergesa - gesa. Mendengar suara burung itu I Gst Ngr Pindha meloncat bangun spontan berteriak "Bersiap, ada NICA". I Gst Ngr Pindha memiliki keyakinan kalau ada burung datang bersuara tentu ada NICA disekitar kita. Jauh dekatnya musuh itu berada, tergantung dari gerak burung itu. Jika tergesa - gesa burung itu terbang berarti musuh sudah dekat. Sedangkan kalau burung itu terbang perlahan - lahan atau agak jauh berarti NICA masih jauh. Selain itu dapat pula diartikan ada patroli musuh (NICA) yang belum mengetahui tempat pejuang. I Gst Ngr Pindha selanjutnya memerintahkan Putu Gde supaya cepat melaporkan kepada I Gst Ngr Rai, bahwa ada musuh (NICA) yang sudah dekat di sekitar kita dan diharapkan bersiap - siap untuk menghadapi. I Gst Ngr Rai selanjutnya memerintahkan supaya segera menyelidiki dahulu dimana musuh itu, atau kita menunggu laporan dari pengawal. Kira - Kira 5 menit kemudian, I Gst Ngr Pindha melihat disebelah timur pada jarak kurang lebih $2 \mathrm{~km}$ debu beterbangan nampak beberapa buah truk mendekatinya. Sementara tanpa diperintahkan para pejuang sudah mengambil cara bertahan setengah sirkel, yakni menghadap ke utara, ke timur dan ke selatan. Para pejuang belum mengetahui secara jelas darimana musuh terlebih dahulu akan menyerang. Para pejuang menunggu kedatangan musuh dalam keadaan tegang. Sempat Letnan Sardja mendahului menyerang dengan tembakan brennya dari sebelah timur dengan jarak kira - kiran 40 meter. Musuh panik dan lari mundur dengan meninggalkan 3 bangkai temannya. Pada waktu itu menunjukkan jam 5.30 sore dimana matahari sudah hampir tenggelam. Para pejuang dengan perasaan tidak sabar menunggu waktu menjelang malam, karena menurut pengalaman mereka NICA tidak berani menyerang lagi dan kembali kepangkalannya. Sekitar jam 7 malam I Gst Ngr Pindha mendengar letusan di sebelah utara dan sesaat kemudian meledak di atas serta mengeluarkan cahaya yang sangat terang. Musuh menembakkan lichthalon tepat diatas pertahanan para pejuang. Kemudian disusul berturut - turut tembakkan lichthalon beberapa lagi. Pada waktu itu alam menjadi sangat terang benderang 
bagaikan di siang hari. Pasukan pejuang yang tidak biasa melihat lichthalon ini menjadi panik. Sementara itu peluru mortir musuh terus berjatuhan. Dalam keadaan kacau para pejuang terus mundur ke arah selatan memasuki sebuah hutan kecil yang gelap (Pindha, 1968a).

Stengun. Senjata ini pernah digunakan oleh tentara NICA setelah mengetahui bahwa pasukan pejuang dari Tabanan datang ke daerah Medewi untuk membantu pendaratan pasukan pejuang dari Jawa. Tentara NICA yang datang ke daerah Medewi bermunculan dengan menyamar sebagai pemuda menggunakan sarung dimana di dalamnya disimpan stengun dalam sarungnya. Dalam hal ini para pejuang kita sangat sulit mengenal teman sendiri serta NICA disisi yang lain sebagai musuh yang juga sama - sama menyamar sebagai pemuda. Ini berarti para pejuang berada di tengah - tengah musuh (NICA), karena itu para pejuang harus meningkatkan kewaspadaannya (Adanyana, 1980).

Senapan Mesin. Sang Merah Putih yang berkibar dengan megahnya di pelabuhan Buleleng, tiba - tiba di turunkan oleh Belanda (NICA) digantikan dengan bendera merah putih biru. Sudah tentu para pemuda pejuang menjadi naik darah. Tentara Jepang yang nampak masih bertugas, diminta oleh para pemuda untuk menurunkan bendera Belanda itu tetap menolaknya. Setelah terjadinya pertengkaran sengit, pimpinan BKR memerintahkan kepada para pemuda untuk menurunkan kembali bendera Belanda tersebut dengan mengganti lagi kembali bendera Sang Merah Putih. Melihat peristiwa itu, Belanda (NICA) melepaskan tembakan - tembakan dari atas kapal. Spontan para pemuda merebahkan diri dan merayap mencari tempat strategis. Tiba - tiba seorang pemuda berlumuran darah. Ketut Merta pemuda yang berasal dari Banjar Liligundi Singaraja, gugur kena peluru senapan mesin. Pada waktu ini pendaratan tentara Belanda (NICA) tidak dapat dibendung lagi. Bendera Sang Merah Putih diganti lagi oleh Belanda dengan mengibarkan kembali bendera tiga warna. Selain itu ada pula penduduk yang ditangkap dan disiksa (Mangku, 1984).

Mortir. Sekembalinya para pejuang dari Tanah Aron, sampailah di tepi pegunungan Batur lalu mereka beristirahat dipinggir danau yang indah itu. Sementara itu pasukan Gajah Merah terus melacak jejak kedudukan para pejuang. Di Desa Belandingan, di pinggir danau Batur para pemuda terlibat lagi dalam pertempuran sengit. Pesawat - pesawat udara dikerahkan dan menghujani tempat tempat peristirahatan para pemuda yang sedang lahap makan ketela bakar. Pasukan MBO segera menyusup ke hutan - hutan, lalu melanjutkan perjalanan masuk kampung ke luar kampung menuju Buleleng. Meraku dkk sampai di Desa Galungan Kecamatan Sawan terus di kejar - kejar oleh mata - mata NICA kemudian melarikan diri bersembunyi di Desa Pegayaman Kecamatan Sukasada. Pada saat itu, seorang rekannya bernama Panji, gugur kena mortir NICA. Mereka lagi melarikan diri menuju daerah Emped Kecamatan Banjar. Disana mereka merasa aman, karena penduduknya masih kompak mendukung pemuda - pemuda pejuang. Di daerah itu Meraku menyamar, kepalanya digundul. Nama sebenarnya diganti dengan nama samaran "Tirtayasa", panggilan sehari - hari "Pak Tir". Tempat persembunyian Meraku yaitu di rumah Pak Muliarsa (Mangku, 1984).

Water mantel. Senjata ini pernah digunakan tentara Belanda (NICA) ketika lewat di kilometer 17 di atas Desa Gitgit. Pada waktu ini pejuang melakukan penghadangan terhadap iring - iringan truck Belanda (NICA) yang penuh dengan tentara. Suara raung kendaraan semakin dekat, terlihatlah beberapa truck Belanda (NICA) penuh dengan tentaranya. Setiap kepala truck terlihat sen- 
jata water mantel yang siap memuntahkan pelurunya. Namun Belanda (NICA) tidak mengetahui bahwa mereka mendapat tantangan dan perlawanan yang sengit dari pemuda gerilyawan kita. Satu persatu truck Belanda (NICA) masuk perangkap namun perintah menembak dari I Gusti Ngurah Mayor sebagai pimpinan belum pula terdengar. Terlihatlah I Ketut Mas telah mengincar sopir truck lewat pisir karabyinnya. Ada atau tidak ada komando, senjatanya meletus dan terlihat truck NICA itu menabrak tebing. Segera disusul oleh lemparan granat dari kawan - kawan pemuda gerilya yang berdekatan dengan truck itu. Selanjutnya Belanda (NICA) menyusul dengan tembakan balasan dengan gencarnya. Tentara Belanda (NICA) pada truck yang lain segera meloncat membela kawan kawannya sehingga terjadi pertempuran sengit. Menurut I Dewa Made Oka korban dari pihak Belanda yang dilihat di atas truck cukup banyak. Belum yang bergelimpangan di jalanan, dimana belum sempat dinaikkan ke atas truck (Zoewella, 1980).

Kapal. Ketika para pejuang sedang sibuk - sibuknya berusaha merebut senjata dari tangan Jepang, kapal Belanda Abraham Grinjs mendaratkan tentaranya di pelabuhan Buleleng. Di pelabuhan mereka merampok bahan - bahan konsumsi seperti : beras, gula, jagung dan lain - lain untuk di angkut ke kapalnya. Yang lebih menyakitkan hati rakyat, mereka dengan lancang berani menurunkan Sang Merah Putih yang sedang berkibar dengan megahnya di pelabuhan Buleleng, sebagai pertanda merdekanya bangsa Indonesia diganti dengan bendera Belanda. Pemuda - pemuda yang bekerja di kantor Hinomaru tidak bisa berbuat apa - apa karena telah ditodong oleh NICA. Rakyat dalam hal ini telah mengetahuinya. Darah rakyat yang mengalir di dada setiap patriot bangsa tidak rela melihatnya. Pada suatu malam pemuda - pemuda pejuang yang telah berkumpul di sekitar pelabuhan menurunkan bendera Belanda dengan menggantikan kembali Sang Merah Putih. Selanjutnya terjadilah insiden yang bersejarah perjuangan rakyat Buleleng sehingga menelan korban seorang pemuda dari Banjar Liligundi bernama Ketut Merta. Beberapa hari kemudian kapal Abraham Grinjs menghilang dari pelabuhan Buleleng, sambil menyeret kapal RI, yang dapat disita dari tentara Jepang (Zoewella, 1981).

Mitraliur, Stengun dan Karben. Pagi - pagi pasukan pemuda pejuang sudah bergerak maju menuju Desa Sawah dekat Desa Belimbing Kecamatan Bajra Tabanan karena mendapat laporan bahwa NICA mengadakan patroli. Hanya lokasinya tidak tetap selalu berpindah - pindah. Sebagian dari pasukan Resimen Ngurah Rai yang dikoordinir Nyoman Sardja Udaya bersama I Gst Ngr Agung Kusuma Yudha, Ketut Dangga, I Gst Bayupati (Bonjoran), Bapak Pegeg dengan beberapa regu anak buah disertai Barisan Banteng (BB) setempat ditugaskan untuk melindungi rakyat memotong padi yang sering diganggu oleh patrol NICA karena rakyat di desa tersebut dipandang memihak pemuda - pemuda pejuang kemerdekaan. Kira - kira jam 10.00 pagi sampailah pemuda - pemuda pejuang di sebuah lereng bukit yang merupakan kebun kelapa. Pemuda - pemuda pejuang tersebut mengaso sebentar, menunggu pemimpin - pemimpinnya berunding mengatur siasat sambil melihat peta. Selanjutnya pasukan menuju puncak bukit kecil melalui sawah, lalu naik ke tempat yang tertinggi. Dari sini berusaha menyelidiki lokasi patroli NICA. Setelah ada laporan, keadaan aman berangkatlah pemuda pejuang secara menyebar menyusuri pematang - pematang di tengah tengah padi menguning. Semuanya masih belum siap bertempur, karena menyangka lokasi NICA masih agak jauh. Terdengarlah tembakan gencar 
mencegat dari daerah atas. Pemuda - pemuda pejuang menjadi sangat kaget. Mereka segera merebahkan diri di tengah - tengah padi tetapi beberapa ada yang sudah kena tembak. Rupanya tentara NICA sudah mengintai dan menunggu dari tempat ketinggian. Mereka menembak dengan mitraliur, stengun dan karben karben sambil bersorak - sorak (Wirya, 1967).

\section{SIMPULAN}

Pada masa revolusi fisik di Bali Belanda (NICA) dalam menghadapi para pejuang menggunakan berbagai peralatan perang modern untuk dapat mengalahkan para pemuda pejuang dalam setiap pertempuran. Belanda menyadari bahwa mereka tidak mudah dapat mengalahkan para pemuda pejuang karena merupakan bekas tentara terlatih baik yang berasal dari pasukan prayoda, peta dan lain - lain. Selain itu pula didukung oleh bekas - bekas tentara Jepang yang memang telah diakui kemahirannya menggunakan senjata yang bersimpati terhadap para pejuang di Bali. Dalam setiap pertempuran tentara Belanda (NICA) banyak yang tewas terkena tembakan para pejuang, oleh karena itu mereka sangat berhati - hati dalam menghadapinya. Dalam posisi sulit tentara Belanda (NICA) sering meminta bantuan pesawat tempur untuk melancarkan serangannya. Untuk mempercepat gerakan pasukan tentara Belanda (NICA) memberi bantuan, mereka menggunakan kendaraan truk. Selain itu Belanda juga sudah menggunakan pesawat telepon dan kapal capung/pipercub untuk menghubungi teman - temannya serta mengetahui kedudukan para pejuang. Demikian pula ketika terjadi pertempuran di malam hari Belanda juga sudah menggunakan peralatan modern berupa lampu penerangan yang disebut lichthalon. Sedangkan untuk operasi di laut menghadapi para pejuang, Belanda setiap saat patroli menggunakan kapal bot dan kapal perang. Dengan peralatan perang modern ini Belanda dapat memperkecil ruang gerak para pejuang dan dapat dengan mudah mengalahkannya. Namun tidak demikian kenyataannya terbukti pada masa revolusi fisik di Bali perjuangan melawan Belanda cukup lama dapat bertahan karena antara pejuang dengan rakyat bersatu.

\section{DAFTAR PUSTAKA}

Adanyana, I. G. N. P. (1980). Mengenang long march ke pulukan tahun 1946. Denpasar: Bali Post.

Bali Post. (1985). Dari album perjuangan (IX)n dua truk pasukan NICA tewas di Sekumpul. Denpasar: Bali Post.

I Nyoman Dekker. (1980). Sejarah Revolusi Nasional. Jakarta: PN Balai Pustaka.

Kartodirdjo, S. (1970). Beberapa Masalah Teori dan Metodologi Sedjarah. In Lembaran Sedjarah No 6. Yogyakarta: Seksi Penelitan Djurusan Sedjarah Fakultas Sastra dan Kebudayaan Universitas Gadjah Mada.

Mangku, P. (1984). Mengenang perang kemerdekaan (II), gerakan tiga belas desember alami kegagalan. Bali Post.

Nasution, A. H. (1977). Sekitar Perang Kemerdekaan Indonesia 2. Bandung: Angkasa.

Pendit, N. S. (1979). Bali Berjuang.

Pindha, I. G. N. (1964). Gempilan perjuangan Physik Di Bali, Men Bolong Memanggil.

Pindha, I. G. N. (1968a). Gempilan Perjuangan Physik Di Bali, Masa - Masa Krisis XIV. 


\section{Lisulturisiolink \\ KULTURISTIK JURNAL BAHASA \& BUDAYA}

Vol. 3, No. 1, Januari 2019, 53

Available Online at https://ejournal.warmadewa.ac.id/index.php/kulturistik

DOI: dx.doi.org/10.22225/kulturistik.3.1.939

Pindha, I. G. N. (1968b). Gempilan Perjuangan Physik Di Bali, Masa - Masa Krisis XXIII.

Poerwadarminta, W. J. . (1976). Kamus umum bahasa Indonesia. Jakarta: PN. Balai Pustaka.

Suparsa, I. N. (1982). Biografi Brigjen Anumerta I Gusti Ngurah Rai. Denpasar: Bali Post.

Suralaga, I. (1982). Puputan Margarana. Bali Post.

Tim Bali Post. (1988). Merasa Berasal dari Satu Ibu. Denpasar: Bali Post.

Wirya, I. P. (1967). Pertempuran di desa sawah Bajra. Denpasar: Bali Post.

Yayasan Kebaktian Proklamasi Daerah Propinsi Bali. (1968). Sejarah singkat Pahlawan Nasional Kolonel Anumerta I Gusti Ngurah Rai. Margarana.

Zoewella, M. (1980). Nostalgia di Kilometer 17. Denpasar: Bali Post.

Zoewella, M. (1981). Kita sedang menikmati kelapa dan gula aren. Denpasar: Bali Post.

\section{DAFTAR INFORMAN}

Arka Sudewa, Ngakan Putu, 1922, Bagian Perlengkapan Staf Ayodyapura, Desa Bujaga (Nongan), Amalapura.

Ardana, I Made Pancer, 1923, Penghubung Istimewa Markas Besar Sunda Kecil dan Ketua Markas Daerah Marga, Desa Antosari Tabanan.

Weda, I Ketut, 1922, Kepala Bagian Siasat Markas Besar Barat Negara, Jalan Punta Dewa Gang II Nomor 4 Negara. 